\title{
AUC Infinity Predicted Normalized by Weight
}

National Cancer Institute

\section{Source}

National Cancer Institute. AUC Infinity Predicted Normalized by Weight. NCI Thesaurus. Code C92321.

The area under the curve (AUC) extrapolated to infinity from dosing time, based on the predicted last concentration, divided by the weight. 